\title{
Lu-Hf and Re-Os isotopic studies of lamproite genesis
}

\author{
G.M. Nowell ${ }^{1}$, D.G. Pearson ${ }^{1}$, and A.J. Irving ${ }^{2}$ \\ 1: Dept. Earth Sciences, Durham University, Durham, DH1 3LE UK. \\ 2:Dept. Geological Sciences, University of Washington, Seattle, WA 98195 USA.
}

\section{Introduction:}

Lamproites are volumetrically insignificant but more than compensate for this by possessing some of the most extreme isotopic and trace element compositions of any terrestrial mantle-derived magmas. Because these exotic rock types can also host world-class diamond deposits there is considerable interest in their origin. Although they are widely thought to represent melts of ancient enriched lithospheric mantle source regions (Mitchell and Bergman, 1991) their occurrence in diverse tectonic settings together with their wide petrographic and geochemical variability remains problematic. Numerous models have been promoted to explain the isotopic and trace element variability of lamproites including contamination or assimilation of crust, contamination of asthenosphere-derived melts with enriched lithosphere, mixing of melts derived from different generations of enriched veins within the lithosphere to melting of variably enriched veins plus depleted lithospheric peridotite (Foley, 1992).
In order to place additional constraints on the possible origin(s) or cause(s) of the extreme isotopic variability defined by lamproites we have analysed almost 40 well characterised lamproites from N. America, W. Australia and Spain for Hf isotopes. A subset of 9 samples have also been analysed for Os isotopes.

\section{Results:}

Hf and $\mathrm{Nd}$ isotope data for the various lamproite localities, including published data for Labrador (Tappe et al., 2007), are illustred in Figures 1 and 2 while Os isotope data is illustrated in Figure 3. The N. American lamproites are divided into two main 'provinces', the NE Utah/SW Wyoming and Monatana provinces, the latter including the Hills Pond lamproite from Kansas since it lies directly on the MontanaFlorida lineament (Mitchell and Bergman, 1991).

Lamproites are characterised by -ve $\varepsilon H f$ values (-10 to -35), in keeping with their enriched -ve $\varepsilon N d$ (-5 to -25) compositions. Such signatures obviously require

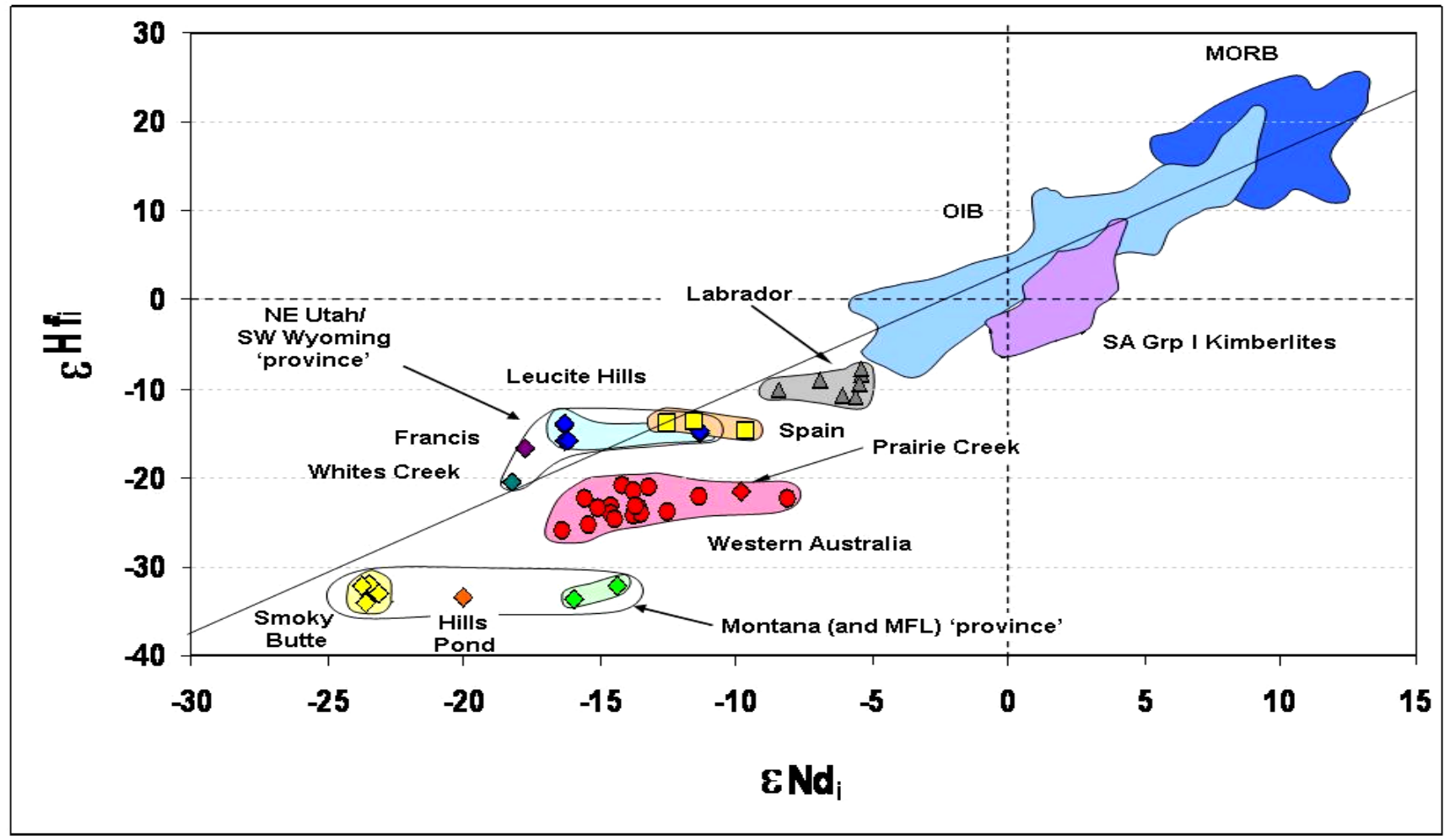

Figure 1. Variation of $\varepsilon \mathrm{Hf}_{\mathrm{i}}$ with $\varepsilon \mathrm{Nd}_{\mathrm{i}}$ for lamproites from N. America (diamonds), W. Australia (circles), Spain (sqaures) and Labrador (Triangles; Tappe et al., 2007). Also shown for reference are the fields for MORB, OIB and Group I kimberlites from S. Africa (Nowell et al., 2004). sources that have experienced long-term enrichment of LREE and depletion of Lu over Hf, i.e., "enriched mantle”. Within each array in Figure 1 there are correlations between selected major elements $\left(\mathrm{SiO}_{2}\right.$, $\mathrm{Al}_{2} \mathrm{O}_{3}, \mathrm{CaO}$ ) and $\varepsilon \mathrm{Nd}$ (not shown).

There are four salient features of the lamproite Hf-Nd isotope data: 
1. They define very obvious shallow arrays that depart from and extend below the mantle regression line of Vervoort et al. (1999) toward -ve $\Delta \varepsilon H f$ values. In this respect, lamproites are quite unique amongst terrestrial magmas. Only the phlogopite lamproites from Leucite Hills, plus the Francis and Whites Creek lamproites plot above the mantle array (Figure 1).

2. Each lamproite 'province' is characterised by a relatively unique $\varepsilon \mathrm{Hf}$ signature (Figure 2) whereas $\varepsilon \mathrm{Nd}$ values show a considerable overlap.

3. The Hf/Nd elemental ratio within each lamproite array is either constant (Montana, Spain) or is variable but shows no correlation with $\varepsilon N d$ (W. Australia Utah/Wyoming).

4. The overall spread in $\varepsilon N d$ values within each 'province' increases as the absolute $\varepsilon H f$ value decreases. The lamproites essentially define a cone that extends and expands from the Labrador to the Montana samples into the enriched quadrant.

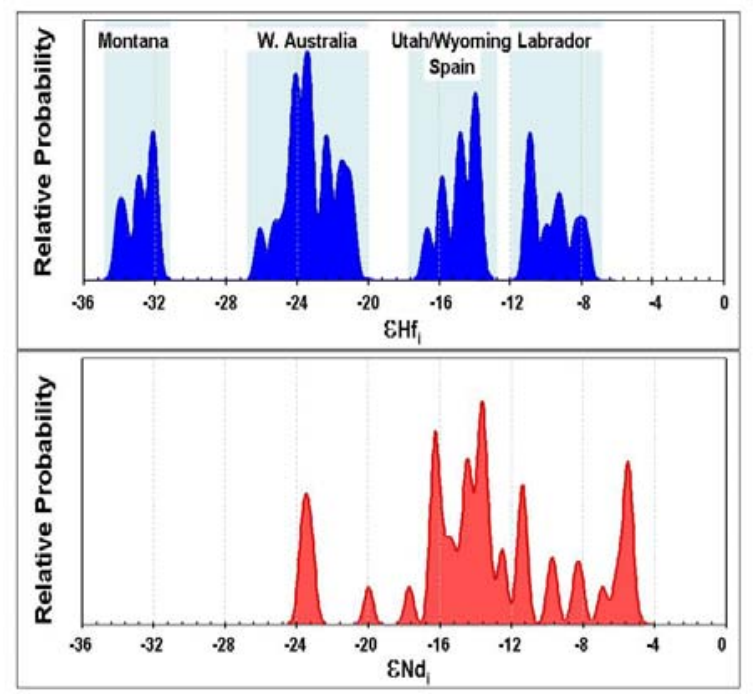

Figure 2. Probability density plot for $\varepsilon \mathrm{Hf}_{\mathrm{i}}$ (blue) and $\varepsilon \mathrm{Nd}_{\mathrm{i}}$ (red) variation in lamproites.

It is also interesting to note that the Utah/Wyoming and Montana lamproite 'provinces' are located on the same Wyoming craton yet have seen two isotopically different reservoirs that apparently have remained isolated from one another (see Irving and Hearn, 2003).

Lamproites also show very diverse Os isotope signatures ( $\gamma \mathrm{Os}-6.8$ to +110 ; Figure 3 ). The least radiogenic Os compositions overlap the high end of the $\gamma$ Os values seen in Group II kimberlites and cratonic peridotites. Lamproites with radiogenic Os isotope compositions far exceed any measured for kimberlites or cratonic peridotites and are more akin to those seen in lamprophyres and kamafugites (e.g., Rosenthal et al. this volume).

\section{Discussion}

The unique horizontal nature of the lamproite Hf-Nd isotope arrays in Figure 1 place quite specific restrictions on models for lamproite genesis. These models must be able to explain the horizontal Hf-Nd arrays and constant or non correlated $\mathrm{Hf} / \mathrm{Nd}$ ratios in each array.

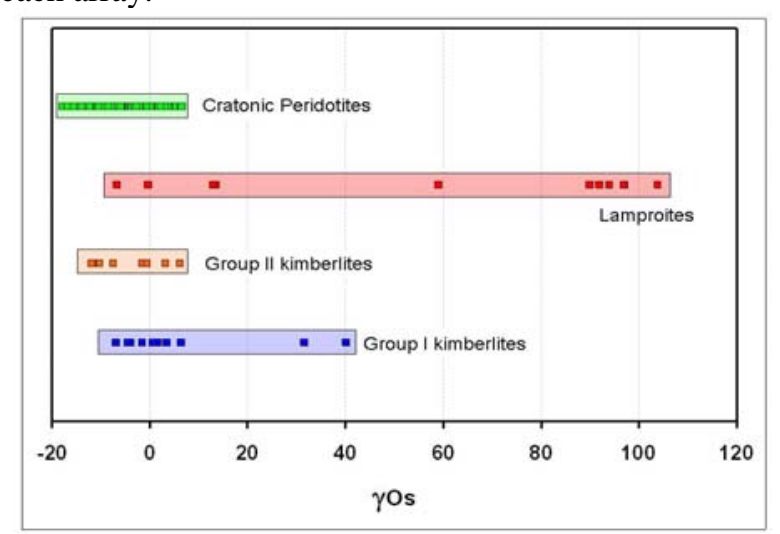

Figure 3. $\gamma$ Os values for lamproites relative to kimberlites and lithospheric peridotites

Mixing/assimilation:- If mixing of mantle derived melts or crustal assimilation models are invoked then the horizontal nature of the lamproite Hf-Nd arrays would require that they are either part of horizontal mixing curves or represent the asymptote of hyperbolic mixing curves. A problem with the former scenario is the lack of obvious endmember components, either to the low $\varepsilon N d$ (with +ve $\Delta \varepsilon H f$ ) or high $\varepsilon N d$ (with -ve $\Delta \varepsilon \mathrm{Hf}$ ) sides of the lamproite arrays.

Griffin et al (2000) postulated that depleted lithospheric mantle has +ve $\varepsilon \mathrm{Nd}$ and -ve $\Delta \varepsilon \mathrm{Hf}$ compositions, plotting to the right of the lamproites in Figure 1, and hence possibly representing a suitable endmember component to explain the lamproite arrays. However, it is now clear that depleted lithospheric mantle is dominated by compositions that are on the mantle array or have +ve $\Delta \varepsilon H f$ values. Nowell et al (2004) also suggested the existence component with slightly positve $\varepsilon N d$ and - ve $\Delta \varepsilon H f$ to explain the Group I kimberlite arrays (Fig. 1) but argued that it was likely to be sublithospheric in origin. Although the lamproites and kimberlites might appear to converge on some common -ve $\Delta \varepsilon H f$ component, if it truly exists, it is unlikely that such a component would represent a suitable endmember to generate the lamproites arrays since each lamproite province would require the -ve $\Delta \varepsilon$ Hf component to have near identical $\varepsilon H f$ and this seems unlikely.

Models based around hyperbolic mixing curves would allow more flexibility with potential endmember components but they would require the endmembers to have contrasting $\mathrm{Hf} / \mathrm{Nd}$ ratios. Since lamproites have very high $\mathrm{Hf} / \mathrm{Nd}(>>0.1)$ the non-lamproite endmember would require extremely low $\mathrm{Hf} / \mathrm{Nd}(\sim 0.005$ to generate the Montana, Utah/Wyoming arrays) to yield the relatively linear, shallow angle mixing curves observed. The major difficulty with a hyperbolic mixing model is the lack of suitable endmembers with low enough $\mathrm{Hf} / \mathrm{Nd}$ and the fact that there is actually no correlation between $\mathrm{Hf} / \mathrm{Nd}$ and $\varepsilon \mathrm{Nd}$ in the lamproite arrays.

Melting of veined source:- The lamproites analysed in this study are charactersied by distinct +ve $\mathrm{Zr}$ and $\mathrm{Hf}$ elemental anomalies and also show strong +ve correlations between $\mathrm{Nb} / \mathrm{Ta}$ and $\mathrm{Zr} / \mathrm{Hf}$. Since the 
$\mathrm{Nb} / \mathrm{Ta}$ or $\mathrm{Zr} / \mathrm{Hf}$ ratios are not correlated with isotopic composition they are not ancient features and must have been imparted on the lamproites by source mineralogy during melting. The $\mathrm{Nb} / \mathrm{Ta}-\mathrm{Zr} / \mathrm{Hf}$ correlation would be consistent with the presence of residual Ti-rich phases (e.g. rutile, ilmenite) in the source while the extremely high $\mathrm{Zr}$ and $\mathrm{Hf}$ abundances might suggest the presence of zircon in the source. This suggests a likely candidate for the source of lamproites is represented by MARID (MicaAmphibole-Rutile-Ilmenite-Diopside) xenoliths.

Unfortuantely, reliable $\mathrm{Nd}$ and $\mathrm{Hf}$ isotope data for MARIDs are almost non existent while trace element data is fairly scarce. Nevertheless, modelling the potential evolution of $\varepsilon \mathrm{Nd}$ and $\varepsilon H \mathrm{Hf}$ in MARIDs based on the available Lu-Hf and Sm-Nd data (Pearson and Nowell, 2002) reveals interesting results. The wholerock MARID compositions used in the modelling have universally low ${ }^{176} \mathrm{Lu} /{ }^{177} \mathrm{Hf}$ ratios $<0.007$ (10x lower than chondrite) such that the Hf isotope composition of the MARID would be invariant and irrespective of its age would reflect the original composition of the melt from which it crystallised. Although the ${ }^{147} \mathrm{Sm} /{ }^{144} \mathrm{Nd}$ ratio of MARIDs is also low (2x lower than Chrondrite) it is sufficiently high and variable that their Nd isotope composition would evolve significantly with time and a range of $\varepsilon N d$ values would result. Figure 4 illustrates the modelled isotopic evolution of MARIDs from a BSE-like initial Hf-Nd isotope composition at $0.5 \mathrm{Ga}$ intervals.

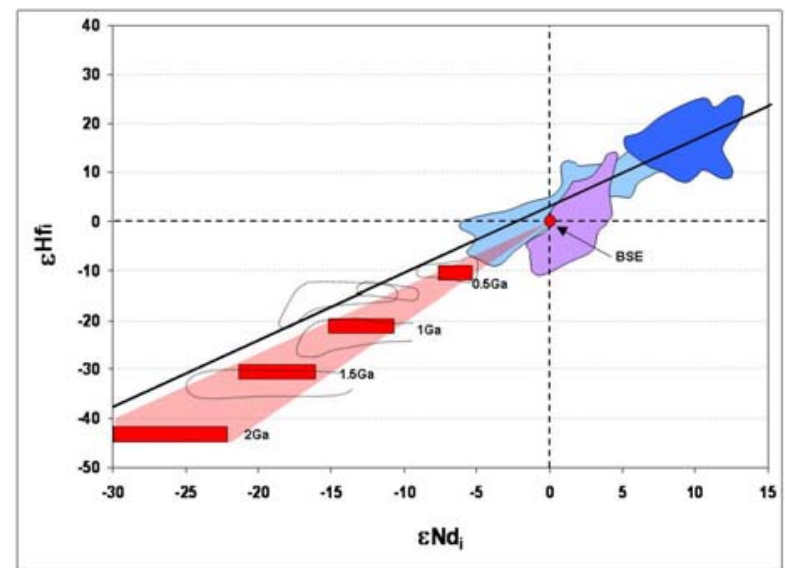

Figure 4. Hf-Nd isotope evolution of MARIDs based on measured elemental compositions. Red rectangles show isotopic composition at $0.5 \mathrm{Ga}$ intervals up to 2Ga. Dashed outlines show composition of the different lamproite provinces from Figure 1.

The modelled $\varepsilon H f$ value for the MARIDs is simply dictated by the storage time of the MARID whereas the variation in $\varepsilon N d$ is controlled by the storage time and the range in $\mathrm{Sm} / \mathrm{Nd}$. The modelled horizontal MARID arrays are very similar to those observed for lamproites in as much as the range in $\varepsilon \mathrm{Nd}$ increases as the $\varepsilon \mathrm{Hf}$ value of the MARID decreases. Since the isotope variation of the lamproites in this model is due to ingrowth rather than mixing there is no requirement for $\varepsilon \mathrm{Nd}$ to correlate with $\mathrm{Hf} / \mathrm{Nd}$ within each provnice, which is consistent with observations.
The modelled range in $\varepsilon N d$ does not provide an exact match for that seen in lamproites (Fig. 4) although this could simply reflect the limited data base for MARIDs and/or the choice of a single initial isotope composition for the MARIDs in the modelling. The slight mismatch would also be expected if MARIDs are not perfect analogues for the lamproite source composition and/or if additional processes such as mixing between MARID-derived melts and others melts possibly with sub-lithospheric origins, have had a modifying effect on their isotopic compositions.

Derivation of lamproites from ancient enriched melt veins within a depleted lithospheric mantle is also consistent with the very radiogenic, and occasionally unradiogenic, $\gamma$ Os values observed in lamproites which probably represent osmium derived from a mixture of metasomatic sulfides and evolved vein compositions.

\section{Conclusion}

The simplest model for the explanation of the Hf-Nd isotope variations of lamproites is one of isotopic ingrowth in a MARID-type veined lithospheric mantle source. Sources of different ages create the discrete arrays observed, even within the same "craton".

\section{References:}

Foley, S. 1992. Vein-plus-wall-rock melting mechanisms in the lithosphere and the origin of potassic alkaline magmas. Lithos. 28, 435-453

Griffin, W.L, Pearson, N.J., Belousova, E., Jackson, S.E., Van Achterbergh, E., O'Reilly, S.Y., and Shee, S.R. 2000. The Hf isotope composition of cratonic mantle: LAM-MCICP-MS analysis of zircon megacrysts in kimberlites. Geochimica Acta Cosmochimica. 64, 133-147

Mitchell, R.H. and Bergman, S.C. 1991. Petrology of lamproites. New York: Plenum, 477pp.

Nowell, G. M., Pearson, D. G., Bell, D.R, Carlson, R.W., Smith, C. B., Kempton, P. D. and Noble, S. R. 2004. Hf isotope systematics of kimberlites and their megacrysts: New constraints on their source regions. J. Petrology, 45, 1583-1612.

Pearson, D.G. and Nowell, G.M. 2002. The continetal lithospheric mantle: Characteristics and significance as a mantle reservoir. Philosophical Transactions of the Royal Society of London. A 360, 2383-2410.

Rosenthal, A., Foley, S.F., Pearson, D.G., Nowell, G.M., Tappe, S. 2008. Origin of kamafugite magmas in the East African Rift of western Uganda. Extended Abstracts 9th International Kimberlite Conference.

Tappe, S., Foley, S.F., Stracke, A., Romer, R.L., Kjarsgaard, B.A., Heaman, L.M. and Joyce, N. 2007. Craton reactivation on the Labrador Sea margins: $40 \mathrm{Ar} / 39 \mathrm{Ar}$ age and $\mathrm{Sr}-\mathrm{Nd}-\mathrm{Hf}-\mathrm{Pb}$ isotope constraints from alkaline and carbonatite intrusives. Earth and Planetary Science Letters. 256, 433-454

Vervoort, J.D., Patchett, P.J., Blichert-Toft, J and Albarede, F. 1999. Relationship between Lu-Hf and Sm-Nd isotope systems in the global sedimentary systesm. Earth and Planetary Science Letters. 168, 79-99 